\title{
PRESENTATION OF EVIDENCE AND FACTFINDING PRECISION
}

\author{
Mirjan DamašKa $\dagger$
}

For at least a century a debate has been raging about the relative advantages of the adversary and nonadversary presentations of evidence as tools in the quest for the truth. ${ }^{1}$ Most of the time this debate proceeded in a mild sfumato of conceptual ambiguity: Differences in the styles of developing evidence were often conflated with differences in arrangements concerning the collection of evidence, admissibility rules, and similar related issues. Beyond that, until quite recently, the arguments advanced were speculative, and information was exclusively in the form of impressions and intuitive insights. In our age, so enamoured of scientific methodology and so desirous of replacing "soft" by

$\dagger$ Professor of Law, University of Pennsylvania.

${ }^{1}$ In the Anglo-American legal culture the discussion of the two manners of prooftaking can easily be traced at least as far as Jeremy Bentham. It is rather difficult, however, to find proponents of the continental style of taking evidence among English and American writers. For a somewhat critical view see R. Schlesinger, Comparative LAw 318, 344 (3d ed. 1970). Even Bentham, so critical of the common law system in many respects, praised the English tradition for "giving the parties the power of examining witnesses." See J. Bentham, A. Treatise on Judicial Evidexce 105 (1825). On the Continent of Europe, the debate about the relative merits of the two evidentiary styles was especially lively after the revolutionary upheavals in the nineteenth century German states. The French revolutionary reforms of 1791 took place much too early to produce a debate on the merits of cross-examination. So strong was the attraction of English institutions in post-1848 Germany, that a provision permitting cross-examination found its way into $\$ 239$ of the German Code of Criminal Procedure of 1877. See The Germas Code of Criminal Procedure $\S 239$ (The American Series of Foreign Penal Codes . No. 10, H. Niebler transl. 1965) [hereinafter cited as Germax CODE]. Old tradition prevailed, however, and to the present day this provision, while alway's a possibility, is simply not used in actual practice. See T. Kleinknecht, Strafprozessordicic 571 (2d ed. 1970). On the vicissitudes of the idea of cross-examination in Germany see J. HERRMANN, DIE REFORM DER DEUTSCHEN HAUPTVERHANDLUNG NACH DEM VORBILD DES ANGlo-AMERIKANisCheN STRAFVERFAHRENS 55-141, 336 (1971). The present author is familiar with an abortive experiment in the 1960's before a Croatian court, in that constituent republic of Yugoslavia, to introduce examination by the parties-in lieu of the traditional judicial examination. This experiment was inspired by the then Chief Justice who, upon his return from America, was very much impressed by the art of cross-examination. This brief episode, poorly prepared, ended in a fiasco.

Examination by the parties, albeit quite differently structured from the AngloAmerican variation, can be found in only a few continental jurisdictions. Scandinavian countries and Spain follow this pattern. See id. 395-96. 
"hard" data, the question almost naturally arises: can at least some themes involved in the debate be translated into a form susceptible of empirical analysis? If the answer is in the affirmative, perhaps products of disinterested science can replace our prejudice, parochialism, and irrational attachments to existing arrangements, no matter how "efficient" these existing arrangements may be. In the present Article I propose to express my reflections on this subject, reflections that were stimulated by a piece of research presented in a series of recent, thought-provoking empirical studies. ${ }^{2}$

My discussion will be in three parts. In the first I shall deal with a number of conceptual preliminaries. Although this part will have its longueurs, our modern eagerness for empirical information must not blind us to the need for careful theoretical preparation before we descend to the empirical plane. Also, as we shall later see, it is mainly through their theoretical underpinnings that values are smuggled into supposedly value-free research paradigms. The second part will analyze briefly the study that provoked me to write these lines, and then go on to offer a prospectus for another empirical study of proof-taking styles. Finally, in the third part, I shall assume that reliable empirical information has been obtained from my suggested prospectus. The significance of such knowledge will then be canvassed from the perspective of the epistemology of the criminal process. I shall concentrate here on the possibility that the "reality" we try to ascertain through evidentiary activity need not be exactly the same in different systems of administering justice.

\section{Theoretical Propaedeutic}

\section{A. Preliminary Remarks on the Object of Proof}

The problem whether the adversary or the nonadversary mode of presenting evidence is better equipped to lead to the truth cannot be analyzed in vacuo. "Truth about what?" is the question that must be answered at the very outset. It must be

2 Thibaut, Walker, \& Lind, Adrersary Presentation and Bias in Legal Decisionmaking, 86 HARv. L. REv. 386 (1972). This study is part of the product of the project "Human Behavior and the Legal Process," supported by a grant from the National Science Foundation. Additional pieces of research have been described in a number of subsequent articles. See Lind, Thibaut, \& Walker, Discovery and Presentation of Evidence in Adversary and Nonadrersayy Proceedings, $71 \mathrm{Mrch}$. L. Rev. 1129 (1973); Walker, Thibaut, \& Andreoli, Order of Presentation at Trial, 82 YALE L.J. 216 (1972). 
determined with sufficient precision what is the referent to which the characterization "truth" or "falsity" applies.

Following in the path of the studies mentioned a moment ago, I shall be concerned solely with issues involved in arriving at a judgment concerning the guilt or innocence of the criminal defendant. But this restriction is far from sufficiently precise. To begin with, consider that the issues disposed of in a judgment do not all have the same epistemological status: The meaning of the symbol "truth" changes considerably as we attach it to its different component parts.

As background for my quick reconnaissance over familiar terrain, imagine a manslaughter charge arising out of reckless driving. The decisionmaker must determine the truth of a certain number of propositions regarding "external facts," such as the speed of the automobile, the condition of the road, the traffic signals, the driver's identity, and so on. The mental operations required to ascertain such "external facts" belong primarily to the sphere of sensory experience. The inquiry here appears to be relatively objective, ${ }^{3}$ and the "truth" about such facts does not seem to be too elusive. ${ }^{4}$

But many "internal facts" will also have to be established in the imagined case. They regard aspects of the defendant's knowledge and volition, to the extent to which these are important for the application of the relevant legal standard. The ascertainment of such facts is already a far less objective undertaking than the ascertainment of facts derived by the senses: processes of inductive inference from external facts are the most frequently traveled cognitive road. Even so, we do not hesitate to accord roughly the same cognitive status to findings regarding these internal facts as we do to findings of external facts. The characterizations "true" and "false" retain their respective meanings.

The situation changes, however, when the facts ascertained must be assessed in the light of the legal standard. Whether a

${ }^{3}$ I say relatively objective, for an element of subjectivity suffuses even such psychological activities as perception. The latter has been shown to be far from a passive registration of stimuli: it depends on interests, previous habits, eren on the creative act of grasping structures, thus implying a degree of inferential construction. Implications of the "creativity" of perception have been traced in various areas. See R. ArnherM, Perceptional Abstractions and Art, in Toward a Psychology of ART 27, 33 (1972); T. Kuhn, The Structure of Scientific Revolutions 126 (2d ed. 1970).

In saying that truth is not too elusire I assume that the decisionmaker has at his disposal reliable informational sources (evidence). 
driver has deviated from certain standards of care-and if so to what degree-are problems calling for a different type of mental operation than that used in dealing with external facts. It is, of course, a matter of free semantic choice whether to characterize the outcome of legal evaluation as "true" or "false," or to use some other pair of symbols. But if one decides to stick with the former, he must recognize that these symbols acquire a different meaning in the new context. In essence they convey the idea that the result of the activity is either correct (coherent) or incorrect (incoherent) within a given framework of legal reference. ${ }^{5}$

Additional issues, whose characterization is exceedingly complex, arise under the Anglo-American system of adjudication, especially in connection with the adjudicator's powers of nullification. ${ }^{6}$ But what I have said so far suffices to indicate that the question about the truth or falsity of a judgment as such, without further specification, is too ambiguous to be meaningful.

Notwithstanding marginal uncertainties and philosophical arguments on some aspects of this problem, it is generally agreed that the presentation of evidence is directed toward establishing the veracity of factual propositions, rather than the correctness of legal reasoning. ${ }^{7}$ In what follows I shall therefore, be restricted solely to the factual segment of the judgment, as the only proper object of proof-taking. Within this factual segment, the problems of findings regarding external facts will bulk largest. They seem a very convenient object of empirical study,

s The distinction between law and fact is often thought to entail the epistemological distinction between fact and value. Fortunately, my purposes do not require me to enter into this difficult and very controversial philosophical issue. Those who agree with my distinction in the text need not take extreme views on the ontological status of values. On such view's see W.R. Frankena, Value and Valuation, in 8 Excyclopedia of Philosophy 229, 231 (1967). On the other hand, even those who claim that they have resolved the Kantian antinomy between the cognitive and the moral will usually admit that-at least for the moment-this dichotomy cannot be obviated. See, e.g., S. Avineri, The Social and Political Thought of Karl Marx 69 (1968). Whatever the philosophical positions on the problem, modern legal systems usually mandate a different approach toward factual and legal determinations (e.g., in cases of factual as opposed to legal uncertainty).

${ }^{6}$ Imagine, as an illustration, that the minority view of Judge Bazelon in United States r. Dougherty, 473 F.2d 1113, 1138 (D.C. Cir. 1972), expressed the true nature of jury nullification. The latter would then involve a "fine tuning" of crude decisional standards. This tuning would, of course, be one-sided, i.e., it would proceed only in favor of the defendant. How, then, can the verdict that distegards the legal instructions be classified? Is it "correct" within the legal universe? Where should the line between ethics and the law now be drawn?

${ }^{7}$ As the reader knows, a legal proposition may sometimes be made an object of proof. But the aim of the evidentiary activity is to prove that a rule exists, and not that a certain legal solution is appropriate in the case. 
in that the processes of their determination are relatively objective.

Where empirical research is contemplated, is this restriction to the factual segment of the adjudicatory activity a workable proposition? Can this segment be extirpated from the whole in any fashion other than through logical analysis? This thought occurs quite naturally to lawyers in the Anglo-American legal culture, where the largely inscrutable jury verdict is so central. But even in continental systems, where decisionmakers are, as a rule, required to provide separate reasons for factual findings and legal determinations, skepticism can easily arise. The mandate to write separate reasons can easily be viewed as implying rationalizations: what is in reality intertwined is presented postfestum in two neatly separated categories. It is indeed the most sophisticated modern view on the continent that, in arriving at a judgment, the mind of the decisionmaker constantly travels from facts to law and back to facts again, in a simulacrum of regenerative feedback. ${ }^{8}$

The constant interaction between fact and law thus cannot be denied. It poses serious problems for the empirical study of the factual segment of adjudication in isolation. If the actual criminal litigation were the object of study, these problems would be insuperable. ${ }^{9}$ But there is another strategy of research. The presentation of evidence can be observed at simulated trials, under controlled laboratory conditions, and under this method the activity may be limited to factual issues only, even to the determination of external facts. And it is this methodology of laboratory experimentation that I shall analyze in the next part.

It cannot be denied that the separation of the factual from the totality necessarily infects the results of the study with an element of artificiality and distortion. The latter element is more pronounced in the Anglo-American system, where the place of

${ }^{8}$ The traditional syllogistic view is moribund, notwithstanding attempts at artificial respiration applied to it by some continental theorists. The view of sophisticated modern writers may be stated briefly as follows. You cannot decide which facts matter unless you have already selected, at least tentatively, applicable decisional standards. But most of the time you cannot properly understand these legal standards without relating them to the factual situation of the case. For a brilliant analysis of this circularity, see Kaufmann, Ueber den Zirkelschluss in der Rechtsfindung, in FESTSCHRIFT Für WILHELM GALLAS 17-19 (K. Lackner, H. Leferenz, E. Schmidt, J. Welp, \& A. Wolf eds. 1973). See also K. Larenz, Methodesilehre der Rechtswissenschaft 471 (2d ed. 1969).

${ }^{9}$ But, for independent reasons, actual systems can hardly be studied to determine the accuracy of their adjudicative outcomes. A formidable problem is how to determine the reality against which the actual disposition of cases could be matched. 
the factual in the whole of the adjudication is less certain than on the continent. But this is hardly news to the scientist who deals with parts of totality all the time. It only means to him that the results must be interpreted with reserve and caution.

But here I am getting ahead of my story; later I shall have more to say about the significance of possible empirical data in this field. In this part, dealing with conceptual preliminaries, I must first turn to the opposition between adversary and nonadversary proof-taking.

\section{B. Two Contrasting Modes of Developing Evidence}

Let me then try to present in some detail what is involved in the opposition of the two proof-taking styles. Because the standard against which the two procedural arrangements are to be studied is to be their relative suitability to lead to the truth, ${ }^{10} \mathrm{I}$ will focus my discussion on those facets that are most relevant to truth determination. Although my method here necessarily implies a degree of imprecision in depicting a much more complex phenomenon, for the sake of brevity I shall limit my discussion to the development of evidence through the examination of witnesses. ${ }^{11}$

\section{The Nonadversary Mode}

Under this variant, there are no separate witnesses for the prosecution and the defense. All witnesses are evidentiary sources of the bench, and it is the judge, not the parties, who has the primary duty to obtain information from them. The parties are not supposed to try to affect, let alone to prepare, the witnesses' testimony at trial. "Coaching" witnesses comes danger-

10 Perhaps the reader should be reminded at this point that the divergent manners of presenting evidence do not exhaust the wide range of evidentiary and procedural variations in the Anglo-American adversary and the continental nonadversary systems. In fact, this contrast is not nearly as important as many others, and probably not even essential to the dichotomy. Remaining within the narrow sphere of factfinding, suffice it to indicate that the opposition between court and party control over what facts are to be determined, and the contrast between the unilateral and bilateral collection of evidence, both generate differences dwarfing those springing from the divergent manner of developing evidence at trial.

${ }^{11}$ Here I shall not consider the special problem of expert testimony. On this problem see Jescheck, Germany, in The Accused: A Comparative Study 246, 252 (J. Coutts ed. 1966); Mueller, The Position of the Criminal Defentant in the United States, id. 87, 112. For an optimistic perspective on the reconciliation of forensic advocacy and technical and scientific testimony see Wolfgang, The Social Scientist in Court, 65 J. Crm. L. \& C. 239 (1974). 
ously close to various criminal offenses of interfering with the administration of justice. ${ }^{12}$

At trial, the witness is first asked by the judge to present a narrative account of what he knows about the facts of the case. His story will be interrupted by questions from the bench only to help the witness express himself, to clarify a point, or to steer the witness back from the labyrinth of utter irrelevancy. ${ }^{13}$ Only when this very informal communication comes to an end does the judge proceed to the interrogation. But even this interrogation process may sometimes strike an Anglo-American observer as more of an informal conversation than a rigorous succession of questions and short answers. Some of the questions go to the credibility of the witness and serve, to a moderate extent, as a functional equivalent of cross-examination. ${ }^{14}$ When the interrogation from the bench has been completed, the two parties are permitted to address questions to the witness, in an attempt to bring out omitted aspects favorable to them, or to add emphasis to certain points on which testimony has already been obtained. In brief, the bulk of information is obtained through judicial interrogation, and only a few informational crumbs are left to the parties.

But how can the judge effectively interrogate? It stands to reason that there can be no meaningful interrogation unless the examiner has at least some conception of the case and at least some knowledge about the role of the witness in it. Thus, under the nonadversary mode of developing evidence, the judge is typically given a file (dossier) containing summaries of what potential witnesses know about the case sub judice.

${ }^{12}$ In a number of continental countries this practice is also contrary to professional canons of ethics, no matter how fantastic this may seem to American lawyers. See, e.g., R. SCHLESINGer, supra note 1 , at 307-08.

${ }^{13}$ The paucity of continental rules on what is admissible evidence permits such an informal arrangement. In some continental countries the failure to permit the witness to offer a narrative account may constitute reversible error. See, e.g., Judgment of Nor. 11, 1952, 3 BGHSt. 281, 284 (dictum) (West Germany).

${ }^{14}$ For provisions on the manner of examining witnesses see the following criminal procedural codes: The French Code of Criminal Procedure \$§ 331-32 (The American Series of Foreign Penal Codes No. 7, J. Moreau \& G. Mueller transl. 1960); Germax Code, supra note 1, \$ 69; C. Pro. Pen. arts. 349-59 (7th ed. R. Alessandri 1973) (Italy); The Code of Criminal Procedure of the RSFSR arts. 150, 158, in Soviet Criminal. Law And Procedure: The RSFSR Codes (2d ed. H. Berman \& J. Spindler transl. 1972); Code of Criminal Procedure art. 216 (Collection of Yugoslav Laws No. 19, M. Damaska transl. 1969) (Yugoslaria).

For the flavor of the examination, as perceived by an Englishwoman, see $S$. Bedford, The Faces of Justice $166-77$ (1961). 
It is easy to see what lies at the core of the described manner of presenting evidence. The decisionmaker is active; he uses the informational sources himself. Information does not reach him in the form of two one-sided accounts; he strives to reconstruct the "whole story" directly.

After the proof-taking phase of the trial is over, the predominantly unilateral style of proceeding comes to an end. Then summations of facts and legal argumentation must be presented. Each side makes his own one-sided assessment of the evidence heard and advances his legal arguments. Exchange is permitted, but the defense must have the last word. ${ }^{15}$ Before the bench retires, the defendant is given the chance to make a final statement, which usually contains a potpourri of what can be classified as testimonial statements and exhortations to render certain decisions.

\section{The Adversary Mode}

Under this arrangement, each party calls his own witnesses and tries to obtain from them information favorable to his case. In order to do this effectively, the party must often prepare the witness for the court appearance; what is later to be testimony is often told in the lawyer's office first. After one party has elicited information from his witness, his adversary takes over the interrogation process. Now the reliability of the other party's witness will be questioned, or an attempt will be made to obtain from him reliable information in favor of the cross-examiner's thesis. And it is through such rival use of evidentiary sources that the factfinding stage of the trial unfolds.

It is true that this adversary presentation may be moderated by the intervention of the factfinder, if he happens to be a judge. ${ }^{16} \mathrm{He}$ can ask questions that "cry out to be asked," or he may obtain immediate clarification of points from the perspective of his cognitive needs. But this judicial intrusion into an adversary development is necessarily limited. Too extensive an intervention may lead to reversal of the judgment. Apart from this consideration, it is exceedingly hard for a judge to ask mean-

${ }^{15}$ It would be erroneous to assume, however, that there will be, in a typical case, a heated partisan argument between the prosecution and the defense. On the impact of the order of presentation see Walker, Thibaut, \& Andreoli, supra note 2.

${ }^{16}$ The jury is largely doomed to passivity, at least until the trial is over. This fact is important from the point of view of experimental psychology. See note 24 infra \& accompanying text. 
ingful questions, innocent as he must be of any prior knowledge of the case. ${ }^{17}$

The essence of this second arrangement is obvious: The decisionmaker is passive, and the informational sources are tapped by two procedural rivals. The information about the facts of the case reaches the adjudicator in the form of two alternating one-sided accounts.

\section{The Perspective of Experimental Witness Psychology}

As I am interested in the problem of which of the two described arrangements leads to more accurate factual findings, the insights offered by experimental psychology become valuable. ${ }^{18}$ And it is just one of many melancholy facts unraveled by this relatively young discipline that all interrogation techniques exert some distorting influences. It is true that we operate tolerably well with rough approximations of what scientists would demand of factfinding precision, and that the psychological pitfalls of the interrogation process can easily be exaggerated. Even so, in their most diluted form, psychological caveats contain sobering messages of humility vis-à-vis our sometimes revered and often overrated techniques of using witnesses. Paraphrasing Dr. Johnson's observation about the lady preacher, one would say that the remarkable thing is not how perfect one or the other arrangement is, but rather that it operates at reasonably tolerable levels.

Let me first allude to a number of problems with the nonadversary mode of developing testimonial evidence. It will be

${ }^{17}$ Frankel, The Search for Truth: An Umpireal Vieu, 123 U. PA. L. REv. 1031, 1042 (1975). The felix culpa of the continental judge is, of course, that he has the dossier of the case before him.

${ }^{18}$ Experimental psychology is quite a flourishing forensic discipline on the continent of Europe. Courses on this subject are offered in law schools, or, at the minimum, in courses on criminal procedure some time is devoted to elementary psychological insights into the sources of inaccurate testimony. Sporadically, courts call upon psychologists to assess the reliability of testimony. This is controversial, however, and is usually limited to juvenile proceedings. See, e.g., Judgment of Dec. 14, 1954, 7 BGHST. 82 (West Germany). See also Blau, Der Strafrechtler und der pSychologische Sachverständige, in 78 ZeITSCHRIFT Für DIE GESAMTE STRAFRECHTSWISSENSCHAFT 153 (1966).

Probably the most widely known continental text on witness psychology is still $O$. Mönkemöller, Psychologie und Psychopathologie der Aussage (1930). The best known French authority on the matter is F. GORPHE, L'APPRÉCIATION DES PREUves EN JUSTICE (1947). For a recent contribution to the field, translated into English, see A. Trankell, Reliability of Evidence (1972). It must be emphasized that many of these books report, in addition to experimental data, a great deal of intuitive and impressionistic information. The extent to which much of it has been anticipated by Jeremy Bentham is striking. See J. BeNtham, supra note 1, at 20-29. 
recalled that the judge must have some prior knowledge of the case in order to become an effective interrogator at trial. But his necessary prior knowledge is, at the same time, a considerable shortcoming from the epistemological point of view. Being somewhat familiar with the case, the judge inevitably forms certain tentative hypotheses about the reality he is called upon to reconstruct. More or less imperceptibly, these preconceptions influence the kinds of questions he addresses to witnesses. More importantly, there is an ever-present danger that the judge will be more receptive to information conforming to his hypotheses than to that which clashes with them. ${ }^{19}$ Although the resulting dangers to accurate decisionmaking are somewhat decreased by the fact that judges are usually aware of this distorting psychological mechanism, the shortcomings of this arrangement cannot be entirely eliminated..$^{20}$

Consider now the adversary manner of developing evidence. It is designed in such a way that the art of suspended judgment can be practiced for a much longer period of time by the adjudicators. They are not driven by the duty to lead an inquiry into forming early tentative theories about the facts of the case. This is, of course, an advantage of the adversary mode. There may be yet another one, although it is much less certain in terms of experimental witness psychology. It is possible that an interrogator "hostile" to the witness may be in a better position to bring out potential conscious or unconscious distortion mechanisms inherent in his testimony (e.g., inaccurate perception, faulty memory images, mystifications, etc.).

${ }^{19}$ Even among experimental psychologists much of this insight is actually intuitive. See J. Herrmann, supra note 1, at 363; A. Trankell, supra note 18, at 27-28; Fuller, The Adxiersary System, in Talks on American Law 43, 44 (H. Berman ed. 1971). Among statisticians this danger is referred to as the danger of "sampling error". See Lind, Thibaut, \& Walker, supra note 2 , at 1142 . It must be borne in mind, however, that there is an independent danger that the judge will be predisposed in favor of a hypothesis of guilt, even before he has learned anything about the case. "It has often been observed," says Bentham, "that judges, in consequence of their very office of being accustomed to see criminals, and to believe readily in the existence of crime, are generally prejudiced against the accused ...." J. BeNrHAM, supra note 1 , at 105 .

${ }^{20}$ See, e.g., Jescheck, supra note 11, at 247. Some continental lawyers, familiar with the Anglo-American system-possibly with a touch of an idealistic view of it-go so far as to call the position of the judge who conducts the examination "psychologically unbearable". J. Herrmans, supra note 1, at 362. But their recommended model, although closer to the Anglo-American style, must not be associated with the latter. This is so not only because the law of evidence is so different on the continent, but also because even those who hold outré views are not prepared to desert the continental paradigm in its attitude toward the discovery of the truth. 
But all this is only part of the story: there are important cognitive costs of the adversary arrangements. As this darker view of the cathedral is seldom illuminated, ${ }^{21}$ let us explore various epistemological pitfalls that lie in the tactical wake of letting two adversaries control the development of evidence at trial. I do not propose here to start the reader on an extended tour of experimental psychology relevant to problems of the rival use of evidentiary sources. It is enough for my limited purposes to call attention to a few of the most salient shortcomings of this arrangement, assuming, at all times, that the parties are not engaging in unethical practices.

It may be in the narrow interest of only one party, or in the common interest of both, that some items of information which the witness possesses do not reach the adjudicator-even though their relevancy in the quest for the truth is beyond dispute. Evidence unsupportive of one's case has no function in the adversary litigation process, nor do matters which the parties decide to leave out of the disputation. And, as the witness is limited to answering relatively narrow and precise qeustions, much information may effectively be kept away from the decisionmaker who presumably is responsible for finding the truth within the limits of the charge. Accordingly, the factual basis for the decision may be incomplete. ${ }^{22}$

${ }^{21}$ But see, e.g., Frankel, supra note 17 (sharp critique of "partisan manipulation" in the use of evidence).

22 I assume that the total number of facts to be established and the total number of evidentiary sources to be used, is the same under both systems discussed. In other words, many variables that influence the completeness of the factual and evidentiary materials submitted to the decisionmaker are held constant under the adversary and nonadversary trial processes. The remark in the text on the completeness of material only refers to the possibility that, as a result of different styles of examining witnesses, the quantum of information obtained from the same witness may be unequal under the two arrangements: the discrepancy between what the witness knows and what he communicates to the decisionmaker may vary significantly under the two modes of dereloping evidence. Let me allude parenthetically, however, to three important variables of crucial importance for the larger problem whether the factual basis for the adjudication of guilt is equal under the adversary and nonadversary systems of structuring the trial.

The first variable concerns the range of facts that the decisionmakers have to determine. Under the adversary system of trial, the parties may agree not to submit certain facts to the decisionmaker even though these facts are within the compass of a charge. Or, one party may decide not to raise an issue relevant to the charge (e.g., a defense). Both these practices are alien to the nonadversary system, in which inter-party arrangements concerning facts are prohibited, and in which it is the court's duty to extend its inquiry to all relevant facts within the limits of the charge.

The second variable involves the different strategies of the search for etidence. Lnder the adversary system, the parties collect evidence to support their respective theses. Under the nonadversary model, the gathering of evidence is primarily the duty of a state 
But there are much more important costs of the development of evidence through rival use of informational sources. The damage to testimony inflicted by the preparation of witnesses is very serious. Parties can hardly be expected to interview the potential witnesses in relatively detached ways that minimize the damage of interrogation to memory images. During the sessions devoted to "coaching," the future witness is likely to try to adapt himself to expectations mirrored in the interviewer's one-sided attitude. As a consequence, gaps in his memory may even unconsciously be filled out by what he thinks accords with the lawyer's expectations and are in tune with his thesis. Later, in court, these additions to memory images may appear to the witness himself as accurate reproductions of his original perceptions. ${ }^{23}$ Another important cost accompanies the cross-examination technique, which, with its challenge to the credibility of witnesses, is a two-edged sword. As Judge Frankel has noted, it is "to a considerable degree . . . like other potent weapons, equally lethal for heroes and villains."24 Even with the best of intentions on the cross-examiner's part, reliable testimony may easily be made to look debatable, and clear information may become obfuscated.

Finally, observe the procedural position of the passive decisionmaker. It is old hat in experimental psychology that people

agency. Obviously, different problems of transmitting information about detected evidence spring from this variation: the adversaries are often reluctant to exchange information about the evidence discovered, while the nonadversary agency entrusted with preparation of the case for trial will, as a rule, transmit all it has unearthed to the court.

The third variable involves different rules of admissibility. Under the adversary system much logically relevant and cognitively valuable information never reaches the factfinder, while the filtering mechanism in the nonadversary system is much cruder.

What is the cumulative effect of these and other variables? It is probably that the total volume of information under the nonadversary system is somewhat greater (assuming that the number of relevant facts is the same). But this does not preclude the possibility that the information obtained under the nonadversary process is less reliable. Problems of "sampling error" may vary greatly in adversary and nonadversary contexts.

${ }^{23}$ See, e.g., A. TRANkell, supra note 18 , at $27-29$. It is true that this process takes place in all interrogation, but the less one-sided the examination the smaller the danger of distortion. Consider the damage inflicted by leading questions alone, which are strictly prohibited to the interrogator under the continental systems.

${ }^{24}$ See Frankel, supra note 17, at 1039. There is the further subtle psychological problem to which I can only allude: the clash between rehearsed testimony obtained during examination-in-chief and the spontaneity of statements obtained on cross-examination. Only one of the ramifications here is surprise. No doubt sudden twists add color, spectacularity, and drama to proceedings, but what is optimal from the point of view of psychology often requires rather boring arrangements, closer to the general continental style. 
display different cognitive needs; they try to reach knowledge and understanding along different paths. It therefore stands to reason that decisionmakers may sometimes require a different method of presentation than that of the clash of two one-sided versions, and that, at a psychologically crucial point, they would sometimes like to ask a specific question of a witness, which in their passivity they cannot do. ${ }^{25}$

Even this brief digression into experimental psychology clearly shows that it is treacherous to make definitive pronouncements about which of the two manners of presenting evidence is a more effective tool in the search for the truth. Speculation about these problems is made even more intractable because the narrow epistemological problem involved can hardly ever be totally separated from a cluster of attitudes and values comprising the larger legal culture. It is thus easy to make impressive speculative arguments on either side of the divide separating the two great modern systems of criminal justice, apotheosizing one or the other proof-taking style. Can this debate be made more objective? More particularly, can empirical tests tell us which evidentiary arrangement, if either, leads to a better approximation of the evanescent reality that we seek to reconstruct in the criminal process? The answer to this question takes me from theoretical preliminaries to the core of my preoccupations.

\section{Laboratory Experimentations with Presentation OF EVIDENCE}

\section{A. The Experiment by Thibaut, Walker, and Lind}

This group of researchers has set out to explore whether the adversary manner of presenting evidence is better suited to counteracting the decisionmaker's bias than the nonadversary. Bias was understood as "the tendency to judge too swiftly in terms of the familiar that which is not yet fully known."26 It was concretely structured so as actually to mean the expectation on the part of the decisionmaker that the criminal defendant is guilty. Before I make a number of comments on this experiment, and try to assess its significance for my theme, this stimulating piece of research must be presented in a nutshell.

25. This applies, of course, to jurors. Seeking clarifications later during deliberation often comes too late.

${ }^{26}$ Thibaut, Walker, \& Lind, supra note 2, at 390 (quoting Lon Fuller). 
A test case was constructed by the researchers. It involved a tavern brawl in the course of which one person, later to be indicted, reacted to an assault by using force. The issue raised by the case was that of the limits of lawful self-defense. Details of the test case were embodied in fifty brief factual statements, half of which were designed under a scaling technique to induce a belief that self-defense was justified, and the remaining half to suggest that the use of force was unjustified. The decisionmakers were selected from among college students. In half of them, the expectation was implanted that the defendant was guilty, while the other half remained "unbiased."27 Panels of student judges were formed, some with biased and others with unbiased students. They were all instructed about two alternative standards for decision: in order to repel an attack a person is not justified in using more force than he thinks necessary (a subjective criterion), or more force than a reasonable person would consider necessary in the circumstances of the case (an objective criterion). ${ }^{28}$ The task of the panels was to decide whether the violent reaction of the defendant to assault was lawful or not.

Next, stylized models of adversary and nonadversary presentation were constructed. In the simulation of the adversary mode, the facts were to be announced to the decisionmakers by two students, seated at separate tables bearing the words "prosecution" and "defense." One student, the prosecutor, was to announce the twenty-five factual propositions damaging to the defendant, while the other, counsel for the defense, was to relate the twenty-five factual statements favorable to the defendant. In the simulation of the nonadversary presentation, all fifty factual statements were to be announced by one person only, but the classification of the facts into two separate groups was to be maintained. Under both simulated models the decisionmakers were expected to be passive, limited to listening to the informational input of a third person (or persons). After completion of some preliminaries that do not concern me here, the simulated trials took place.

Among the results of this experiment relevant to my discussion, the following were most important. In unbiased judges, the

27 On the technique of "biasing" the subjects, see id. 394.

28 The application of these two standards, the first of which probably implies a higher degree of culpability than the second, creates certain subtle decisionmaking problems. However, in view of the fact that in simulated trials there is less reluctance to convict than in actual trials, these problems are probably not too important and shall not be explored here. 
different presentation of factual statements failed to produce a statistically significant difference in the determination of guilt. But in biased judges, there was a statistically significant higher number of decisions of guilt (i.e., decisions consistent with their bias) in the simulated nonadversary presentation than in the simulated adversary presentation. This difference was most pronounced in the interim measurements taken after biased decisionmakers had been exposed, under the nonadversary mode, to presentation only of the factual statements designed to create the belief that the defendant was probably guilty. Those exposed to the adversary presentation better resisted this bias.

In passing now to the discussion of this experiment, I want to examine only a few aspects of its theoretical foundation, and to concede the validity of its findings. It appears on first impression that the experiment has supplied valuable data for the theme that concerns me in this Article. A closer look reveals that this is not the case.

The researchers tell us that their investigation focused on two modes of presenting evidence. ${ }^{29} \mathrm{But}$, in light of my brief initital sketch of the adjudicative process, the reader must already have had second thoughts about the accuracy of this claim. In the experiment, the decisionmakers were not presented evidence and then asked to ascertain facts. Instead, they were conveyed propositions of fact and apparently expected to assume that these were true. There is no indication in the description of the study that the decisionmakers were supposed to question the accuracy of factual propositions that were transmitted to them. What then is a better description of their activity? They were supposed to implement one of two very general decisional standards in light of the supplied factual information and were expected to arrive at a decision of guilt or innocence, at a legal determination. Under the subjective legal standard (whether the defendant believed that the use of force was necessary) they were also asked to establish "internal" facts (the beliefs of the defendant). But even on this point there was no outward evidentiary activity of any sort: The decisionmakers were engaged solely in inferences and evaluations. Consequently, what the researchers actually studied was the effect of unilateral as opposed to bilateral announcements to the adjudicator of the results of already completed evidentiary activity. This, to my mind, more nearly re-

29 Thibatt, Walker, \& Lind, supro note 2, at 389. 
sembles closing arguments before the judge than the presentation of evidence to him. ${ }^{30}$

Was the experiment addressed to the problem of which arrangement is more likely to produce the truth? Of course not. If the main activity involved in the simulated adjudication was indeed the making of a legal decision, ${ }^{31}$ it stands to reason that this decision cannot be characterized as "true" or "false" in the same sense in which this characterization applies to the objects of my concern-factual findings. Borrowing a phrase from Wittgenstein, one can say that different language games are involved. Nor were the decisions evaluated in terms of their "coherence" or "correctness" within the legal universe. No independent criterion was supplied against which to judge whether the defendant's reaction to the assault was indeed lawful or not. The researchers' direct concern was the efficacy of the two different arrangements in counteracting the adjudicator's bias, understood as an inclination to follow the expection that the defendant is guilty. It seems, however, that those who designed the experiment may have hoped to provide indirectly some data on the question of which arrangement leads to greater accuracy. There is a passage in their text pointing to the widespread belief in the correlation between the adjudicator's bias (read "expectation of guilt") and an erroneous decision. ${ }^{32}$ But one cannot rule out the possibility, no matter how unpleasant the thought, that those who followed their bias made the "correct" finding of unlawfulness, while those who resisted it erred. It would not be the first beautiful assumption slain by ugly facts. ${ }^{33}$

${ }^{30}$ Of course, the difference remains that the judge is not expected to assume the accuracy of the factual underpinnings of the partisan closing arguments.

31 An argument could be made that the supplied "objective" standard for decision (i.e., what force a reasonable person would believe necessary) involves a factual determination. Although it is true that many such standards could be made the objects of surveys and similar sociological factfinding techniques, they are actually treated as normative propositions.

${ }^{32}$ See Thibaut, Walker, \& Lind, supra note 2, at 390.

${ }^{33}$ It is true that an arrangement that better counteracts the adjudicator"s predisposition toward guilt is better equipped to minimize the number of false convictions. But whether such an arrangement leads to the truth in a greater number of cases is another question. Minimizing the total mumber of inaccurate outcomes and minimizing false positives are two different concerns. As long as one remains in the sphere of procedural epistemology, the two issues must not be confused. The question about the optimal distribution of error is based on values other than the desire to establish the truth, and thus falls outside the purview of this article.

There is another problem, however, that deserves brief mention in connection with the impact of the decisionmaker's bias in the described experiment. It concerns 
I recognize, of course, that my comments so far may be more conceptualistic than the subject permits. They may also be wrong. Let us assume therefore that the researchers were indeed focusing on the presentation of evidence, and that they were in fact measuring, albeit indirectly, the truth-finding potential of the two different evidentiary arrangements. The problem then becomes whether their two simulated models express the opposition between the adversary and nonadversary development of evidence. My answer, clearly following from my previous discussion of this contrast, is definitely in the negative.

As I understand it, and mine is not an unorthodox conception, the quintessence of the nonadversary arrangement is that the decisionmaker be active, that he develop the evidence himself. ${ }^{34}$ If this feature is absent, so are all the possible advantages of the arrangement. And it is precisely this characteristic of proof-taking that was not included among the planned variations used in constructing the simulated models. Under both models the decisionmakers were passive listeners, a desirable stance only within the adversary mode. Under both models adjudicators were exposed to an informational input that neatly classified factual propositions as either favorable or damaging to the defendant. This again is true only to the adversary style. The only difference between the two arrangements was that the dividing line between the two kinds of information was thrown into sharper relief under what was supposed to be the simulation of the adversary model, by assigning the announcement of different categories of facts to different persons. The contrast between adversary and nonadversary modes of presenting evidence can hardly be found in the simulated model. Nor is the contrast devised by the researchers expressive of continental as opposed to Anglo-American styles of arguing before the court. All modern nonadversary systems organize arguments in a disputational

the balanced nature of the test case. The factual basis for the legal decision was in equipoise: twenty-five propositions suggested guilt and twenty-five propositions indicated innocence. Jean Buridan would surely claim that this is exactly the situation he illustrated with his donkey between two equal haystacks: In order to have any movement, an impetus must first be provided. See M. Clagett, The Science of Mechasics IN the Middle Ages 537 (1959). The study of bias in this unusual situation is sui generis. Imagine that the adjudicators in this case were further instructed about the reasonable doubt standard. It is not inconceivable that, even with biased decisionmakers, the two variations would show no statistically significant difference.

${ }^{34}$ The researchers recognized this but still believed that their simulation represented "considerable movement" toward pure models, at least with regard to the nonadversary system. Thibaut, Walker, \& Lind, supra note 2, at 388, 391-94. 
form, and whatever differences remain were not picked up by the simulation.

In summarizing my comments about the experiment, I am led to conclude that the researchers promised one thing and delivered another. They supplied empirical support for the following hypothesis: In close cases a bilateral summation of established facts is better suited than a unilateral one to counteract the decisionmaker's inclination to render a judgment in accordance with his expectation that the defendant is probably guilty. They told us nothing about the relative advantages of adversary and nonadversary modes of presenting evidence in the divination of truth.

Notwithstanding mislabeling and possible weaknesses of theoretical preparation, I find the research by Thibaut, Walker, and Lind very useful and stimulating. My thumbnail sketch of their experiment was too thin to convey its many, although debatable, methodological refinements and to do justice to the ingenuity that went into the research. Inspired by the latter, I shall offer a cursory sketch of another experiment which may shed some empirical light on the operation of the two divergent manners of presenting evidence.

\section{B. An Alternative Test Proposal}

If one wants to embark on a study of factfinding accuracy he must, of course, establish criteria of reality. ${ }^{35}$ This is neither too costly nor overly difficult if simulated trials are contemplated. For instance, having written certain facts into the script, one could film an event simulating a crime (for example, a manslaughter by a drunken driver), and by careful and repeated viewing of the motion picture compile an exhaustive list of all facts that a viewer of the film might possibly observe. Criteria have now been obtained for checking the accuracy of future factual findings at the simulated trial.

What we need next are witnesses. A number of persons should be invited to watch the motion picture closely. How this should be arranged in detail is, of course, a matter for experimental psychologists to decide. A false witness could be pro-

${ }^{35}$ By reality I mean the world as mediated by our experience and as locked into the system of our classificatory scheme. It is this "human" reality, no matter what its ultimate "true nature," that we are concerned with in the factual segment of ctiminal law adjudication. 
duced and later planted at the simulated trials to measure the extent to which false testimony can distort the outcome, if this variable is of interest.

Finding suitable factfinders and defining their role may be more difficult. As is known, the nonadversary trial calls for factfinders who are both skilled examiners and adjudicators; such people are hard to come by in countries where the personal union of the investigator and the adjudicator is viewed askance. Even so, it would probably be too pessimistic to expect the problem to be insurmountable. ${ }^{36}$ To hold constant factors stemming from the different composition of various decisionmaking bodies, single judges seem on many counts to be preferable to panels.

Much as in the preceding experiment, some judges would then have to be implanted with an expectation that the defendant is guilty (they would have to be biased). It is true that the sole task of the judges will be to establish a factual basis for a finding of guilt, but this by no means implies that factfinding, even in the context of a simulated trial, is such a "neutral" activity as not to be influenced by bias. ${ }^{37}$ This bias could be induced, for instance, by exposing some of the future judges to series of film clips, designed to induce specific preconceptions about what usually happens under circumstances similar to those in the filmed event.

Following the simulated trials, the task of the judges would be to submit a list of precisely described factual findings about the event. Naturally, standards of what facts are relevant would have to be developed and made uniform for all judges, no matter what the mode of trial. The expected decision would be in the nature of a special rather than a general verdict.

Nonadversary development of evidence would be designed in such a way that the factfinder would invite witnesses to present a narrative account, and then submit them to interrogation. There would be a possibility of confronting witnesses whose tes-

${ }^{36}$ If the experiment were conducted in a continental country it would not be difficult to find suitable decisionmakers, but it would be difficult to find examiners qualified to perform along the lines of the Anglo-American direct- and cross-examinations.

${ }^{37}$ How bias can affect factfinding in our context is easy to show. Even if conduct is not a crime, preconceptions about what has happened influence the factfinder's inquiry (where he conducts it) and sensitize him more to certain information than to other information. Expectation also affects the mechanism of "logical completion" of memory images. See A. TRANKELL, supra note 18, at 18. 
timonies clashed. If thought necessary for effective questioning, a file containing brief summaries of what witnesses saw could be supplied to decisionmakers. In order to avoid undue complexity in an experiment under laboratory conditions, there would be no subsidiary questioning by counsel, and many other characteristics of the nonadversary model would not be replicated.

The adversary manner of presenting evidence would be designed to unfold through examination-in-chief and crossexamination of witnesses before a passive factfinder. For this skilled lawyers would be needed, and each would be assigned a number of "his" witnesses to prepare for testimony. The methodological problem would be, of course, how to create a contest between two counsel. Although the details of the arrangement would require a great deal of ingenuity on the part of the experimenters, its basic contours seem easily discernible. For: instance, lawyers could be divided into two groups; one would be invited to try to prove the factual basis for a conviction on the manslaughter charge, the other to establish the facts supporting a verdict of innocence. At all times the circumstances would have to be checked to determine whether the factfinding efforts under the two modes of proof-taking are directed toward the same facts.

As a result of four variables (adversary versus nonadversary proof-taking, and biased versus unbiased factfinders) four types of differently structured simulated trials would have to be held. The decisionmakers would then be expected, following the criteria of relevancy, to hand in their factual findings. These findings would be measured and statistically analyzed, at least insofar as the findings under the adversary and nonadversary presentation overlap and concern the same facts. ${ }^{38}$

The results could be quite interesting. Those who believe in the superiority of the continental style would probably expect that the latter, even when used to a biased judge, would still yield a more precise factfinding result. Those who believe in the potency of cross-examination would probably expect this weapon to secure better results even before a biased judge. In any event,

${ }^{38}$ It is possible that, notwithstanding the uniform criteria of relevancy, one or another mode comes up with a richer harvest of facts. For instance, the partisan perspective followed by the adversary system may embrace within its two narrow searchlights a smaller number of facts than the unfocused narrative of the witness in the nonadversary system. Accuracy of findings must then be measured only with regard to the factual overlap. 
data obtained would, I believe, tell us much more about the two differing styles of proof-taking than the study described before.

\section{iII. A Glance at a Larger Epistemological Problem}

A much debated problem has now hopefully been presented in a form susceptible of empirical testing. Quite unrealistically, let me assume that experimentation has proven conclusively that one manner of presenting evidence leads to more precise factual findings than the other. What would be the significance of such an empirical datum for the question of which evidentiary arrangement is preferable?

As the criminal process is not an untrammeled exercise in cognition, it does not take much imagination to realize that from the standpoint of other important values, an epistemologically inferior technique may on the whole be preferable. Preoccupation with the rationality of one component can be irrational when judged from the point of view of the entire scheme. ${ }^{39}$ But the perspective of such other values does not concern me here, limited as I am to the sphere of the quest for truth in the criminal process. Observing, then, the presentation of evidence in this narrow, artificial light, would the datum mentioned above not put an end to the debate about the relative merits of the two manners of presenting evidence? To answer this question $I$ must, before closing, return once again to the object of prooftaking which I touched on in a preliminary fashion at the beginning.

An argument can be made that as we move from the continental to the Anglo-American procedural system, a subtle change takes place. It used to be much more pronounced than it is in our century, but its contours are far from indistinct. Anglo-American decisionmakers are traditionally strongly attached to individualized justice and strive to arrive at the just

39 Elsewhere I have considered a few aspects of the trade-off between the quest for truth and a few other procedural values. See Damaška, Evidentiary Barriers to Conviclion and Two Models of Criminal Procerlure, 121 U. PA. L. REv. 578-89 (1973). But problems are much more complex than those of establishing a positive goal and various constraints on it. It may be that various ingredients that go into the mix of procedural values are not amenable to analysis at all; their perception may be like artistic perception, impervious to quantification and systematization. Thibaut, Walker, and Lind hint at an aspect of this possibility, relying on a passage from Tribe. See Thibaut, Walker, \& Lind, supra note 2, at $390 \mathrm{n} .14$. Presentation of evidence may, on this view, be an activity whose end lies in itself. If a procedural arrangement becomes indeed such an Aristotelian entelécheia, evaluating it in terms of outside objectives is utter nonsense. See Aristotre, Metaphysics 1050a22-35. 
result in the light of concrete circumstances of the case: Justice to them can hardly be separated from details. The continental decisionmakers are relatively more concerned about uniformity and predictability: they are much more ready than the commonlaw adjudicator to neglect the details of the case in order to organize the world of fluid social reality into a system. ${ }^{40}$

This unequal value orientation leaves an unmistakable imprint on decisional standards in the two legal cultures. Those of the Anglo-American judge are traditionally in the form of precedents. It is typical of precedents that the decisional standard contained in them can hardly be translated into an abstract rule. What is important in factual details of such professional anecdotes can be approached from different perspectives, and hardly can be stated with precision. ${ }^{41}$ Meanwhile, standards of the continental judge are preferably in the form of precise rules, contained in authoritative texts. The consequence of this difference in standards for factual determination, and therewith for the object of proof-taking, is not difficult to see. The AngloAmerican criteria of relevancy make the factual basis of a decision closer to social reality, where fact and value are intertwined. The foundation of the continental decision is drained of much of the concreteness of real life situations. It is frozen, as it were, into a relatively artificial world of technical relevancy, untainted by social conflict. Now, the more one is removed from the fullness of life, the more limited but also the more precise is our knowledge: there is one fixed perspective. On the other hand, the closer one remains to the complexity of real life processes, the more encompassing but also less certain is one's understanding: as in cubism, our sensations come from multiple viewpoints and there is more than one side to every story. The truth appears elusive, often a matter of feeling and intuition.

If I am right, and there is indeed a subtle discrepancy in the "realities" constituting the object of proof in the two systems, then it is only natural that methods of inquiry into such different realities need not be exactly the same. The continental system

4" See Damaška, Structures of Authority and Comparatize Criminal Procedure, 84 Y ALE L.J. 483, 509 (1975). See also C. Radbruch, Der Geist des exglischen Rechrs 48 (3d ed. 1956).

"1 Kuhn has distinguished knowledge embedded in "shared exemplars" from knowledge embedded in rules. The former is "misconstrued if reconstructed in terms of rules that are first abstracted from the exemplars and thereafter function in their stead." T. KuHN, supra note 3, at 192. 
would tend to embrace a paradigm closer to that of scientific investigation. ${ }^{42}$ The Anglo-American system, where truth is so much a matter of perspective, would tend to espouse a variation of the dialectic method for the divination of the elusive truth. ${ }^{43}$

Note how differently the "scientific" and the "dialectic" paradigms conceive of the ideal position of the judge. In the continental jurisdictions, the judge who has prior knowledge of the case will not automatically be viewed with suspicion. He is, mutatis mutandis, like a scientist who, by having formed tentative theories about the object of his exploration, has not thereby surrendered his claims to impassivity. Only when he has a personal stake in the decision, or when his mind is closed on the case, may there be a ground for disqualification. ${ }^{44}$ In the Anglo-American system, prior knowledge of the case on the part of the judge is more readily associated with bias. The reasons for this are quite straightforward. If the judge obtains knowledge about the case independently of the dialectical process of courtroom inquiry, he can hardly decide which side emerged victorious from the disputation about the truth; he will be siding all the time with the party whose version of the facts accords with his independent knowledge. ${ }^{45}$ Nor is this all. Quite ominously, the two parties will no longer be stimulated to invest their energies in a full adversary clash, for that method of inquiry will no longer be decisive, having formed a mésalliance with an alien epistemological approach. ${ }^{46}$

42 And, because the legal system is more closed, formal logic becomes a very potent weapon of argument and analysis.

${ }^{43}$ And, because the legal system is more open-ended, formal logic loses a great deal of its importance. See, e.g., M. Markovic, From Affluence to Praxis 32, 33 (1974).

it Consequently, the main approach on the continent is not to deny the judge familiarity with the dossier, but rather to make the dossier shorter so that no final opinion on the case can be obtained form its study. See J. Herrmann, supra note 1, at 397-401.

45 Continentals are often puzzled at the requirement that jurors have no knowledge of any facts whatsoever. A good example of this was the continental reaction to the voir dire in the trial of Jack Ruby, who was seen by millions on TV to have shot Lee Harvey Oswald. What does the Anglo-American system want, a continental mind is inclined to ask? Surely it does not want that the courtroom process of truth divination come up with a finding contrary to the TV "reality." Why then should the Anglo-American system assume that those who know about the killing will be partial judges in other matters that must be determined?

${ }^{46}$ The particular conception of bias found in the Anglo-American system surfaces in the study by Thibaut, Walker, and Lind. The orientation of their "comparative" research has a built-in common law slant. But, for the same reasons, the research paradigm suggested by me expresses a continental perspective, in that the fragmentation of the "totality" of adjudication, and the emphasis on precise determination, do less violence to the continental than they do to the Anglo-American system of administering justice. 
In light of this discussion, what is the significance of empirical data telling us that one mode of presenting evidence leads to more precise factual findings than another? It is obvious that this small empirical pied-à-terre does not take us very far, even within the limited horizons of procedural epistemology. This is not, however, to imply that efforts at gaining empirical information on evidentiary arrangements are of no consequence at all. Even when empirical information is available, the debate mentioned at the beginning of this article will, of course, go on. But it will be conducted on a partially more objective basis, with the help of at least some verifiable criteria. Claims like the Wigmorean one that "cross-examination is the greatest legal engine ever invented for the discovery of truth" 47 could then be analyzed with more understanding and accepted less on faith. And, if one believes that a dose of skepticism about one's own system is healthy, this in itself is no small gain.

47 J. WigMore, EvideNce $§ 1367$, at 29 (3d ed. 1940). 